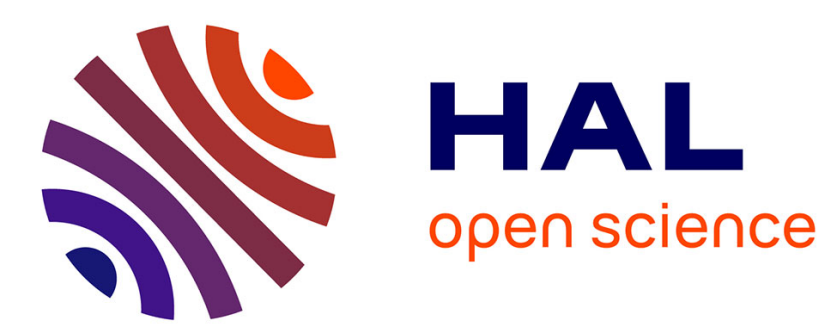

\title{
Development of an attrition evaluation method using a Jet Cup rig
}

Benjamin Amblard, Stéphane Bertholin, Carole Bobin, Thierry Gauthier

\section{To cite this version:}

Benjamin Amblard, Stéphane Bertholin, Carole Bobin, Thierry Gauthier. Development of an attrition evaluation method using a Jet Cup rig. Powder Technology, 2015, 274, pp.455-465. 10.1016/j.powtec.2015.01.001 . hal-01149043

\section{HAL Id: hal-01149043 \\ https://hal.science/hal-01149043}

Submitted on 6 May 2015

HAL is a multi-disciplinary open access archive for the deposit and dissemination of scientific research documents, whether they are published or not. The documents may come from teaching and research institutions in France or abroad, or from public or private research centers.
L'archive ouverte pluridisciplinaire HAL, est destinée au dépôt et à la diffusion de documents scientifiques de niveau recherche, publiés ou non, émanant des établissements d'enseignement et de recherche français ou étrangers, des laboratoires publics ou privés. 


\title{
Development of an attrition evaluation method using a Jet Cup rig
}

\author{
Benjamin Amblard, Stéphane Bertholin, Carole Bobin, Thierry Gauthier
}

IFP Energies Nouvelles

Rond Point de l'echangeur de Solaize

BP 369360 Solaize

\begin{abstract}
There is presently very little information available concerning long term operation with group B oxygen carriers for the Chemical Looping Combustion (CLC) process. It is therefore difficult to predict the attrition at industrial scale based on existing tools and methodologies for the different oxygen carriers available. The CLC process is similar in its configuration to the Fluid Catalytic Cracking (FCC) process with particles circulating in a loop between different reactors. Therefore for the CLC process development perspectives, it is interesting to compare the different oxygen carriers with a FCC catalyst of which data at industrial scale are available.
\end{abstract}

A method to compare the mechanical resistance to attrition of solids from different fluidization groups was developed in this work. In order to deal with small amount s of particle samples, experiments are conducted using lab scale testing with a Jet Cup rig . Two solids of interest were considered in this study, a Group B oxygen carrier with a density of $3600 \mathrm{~kg} / \mathrm{m}^{3}$ and a mean particle diameter $\left(\mathrm{dp}_{50}\right)$ of 180 microns, and a group A FCC equilibrium catalyst with a particle density of $1450 \mathrm{~kg} / \mathrm{m}^{3}$ and a mean particle diameter $\left(\mathrm{dp}_{50}\right)$ of 70 microns.

First, we defined a new attrition index that does not depend upon a given particle size. This index is based on the total percentage of particles generated by attrition and it is called TPGI (Total Particles Generated Index). This index also gives the possibility to estimate the maximum diameter of particles generated by attrition.

It was found that attrition in the jet cup is proportional to the contact frequency between the air jet and the particles. Therefore it is necessary to estimate the particles circulation within the air jet for each solid tested in order to make sure that particles go through the same mechanical stress. For this purpose, a CFD study using Barracuda ${ }^{\mathrm{TM}}$ was carried out on the two solids of interest. CFD results showed that in order to have the same circulation of particles in the air jet, therefore the same mechanical stress, tests should be carried out with the same initial volume of particles. It is important to notice that this conclusion is valid for the two solids of interest, another CFD study should be done for solids with different properties.

Finally, the particles mechanical resistance is characterized by the TPGPI increase rate with respect to the test duration. This parameter is then be used to compare the solids tested, the oxygen carrier being more resistant than the FCC catalyst in this study case. 


\section{Introduction}

Chemical Looping Combustion (CLC) is an oxy-combustion like technology for $\mathrm{CO}_{2}$ capturing where oxygencarrying particles are used to supply oxygen for combustion [1]. The process uses dense group A or group B metal oxide as an oxygen carrier to transfer oxygen in a circulating fluidized bed from an air reactor to a fuel reactor where a combustion takes place. The choice of the oxygen carrier particles is a key parameter for the process development. Apart from reactivity and oxygen transfer capacity, it is also important to study attrition. Indeed during their life-time, particles go through a high mechanical stress due to their circulation between the different reactors. Particles with low mechanical resistance will produce fines which can cause many problems such as inventory losses and bad solids circulation. Furthermore, this may impact significantly the operating costs of an industrial unit. The present study is part of the process studies conducted together by IFP Energies nouvelles and Total to develop a Chemical Looping Combustion process [2] [3] [4].

Particles belonging to group B powders may be more suitable to control circulation in the CLC process [5] or to separate more easily oxygen carriers from unburnt particles [2]. However, there is presently very little information available concerning long term operation with group B oxygen carriers and industrial data are not available for the CLC process. It is therefore difficult to predict the attrition at industrial scale based on existing tools and methodologies for the different oxygen carriers available. One idea is to compare the different potential oxygen carriers with catalyst used for the Fluid Catalytic Cracking process (FCC), where industrial attrition data already exist. Indeed, the CLC process is similar in its configuration to the FCC process with particles circulating in a loop between different reactors as shown in Figure 1.

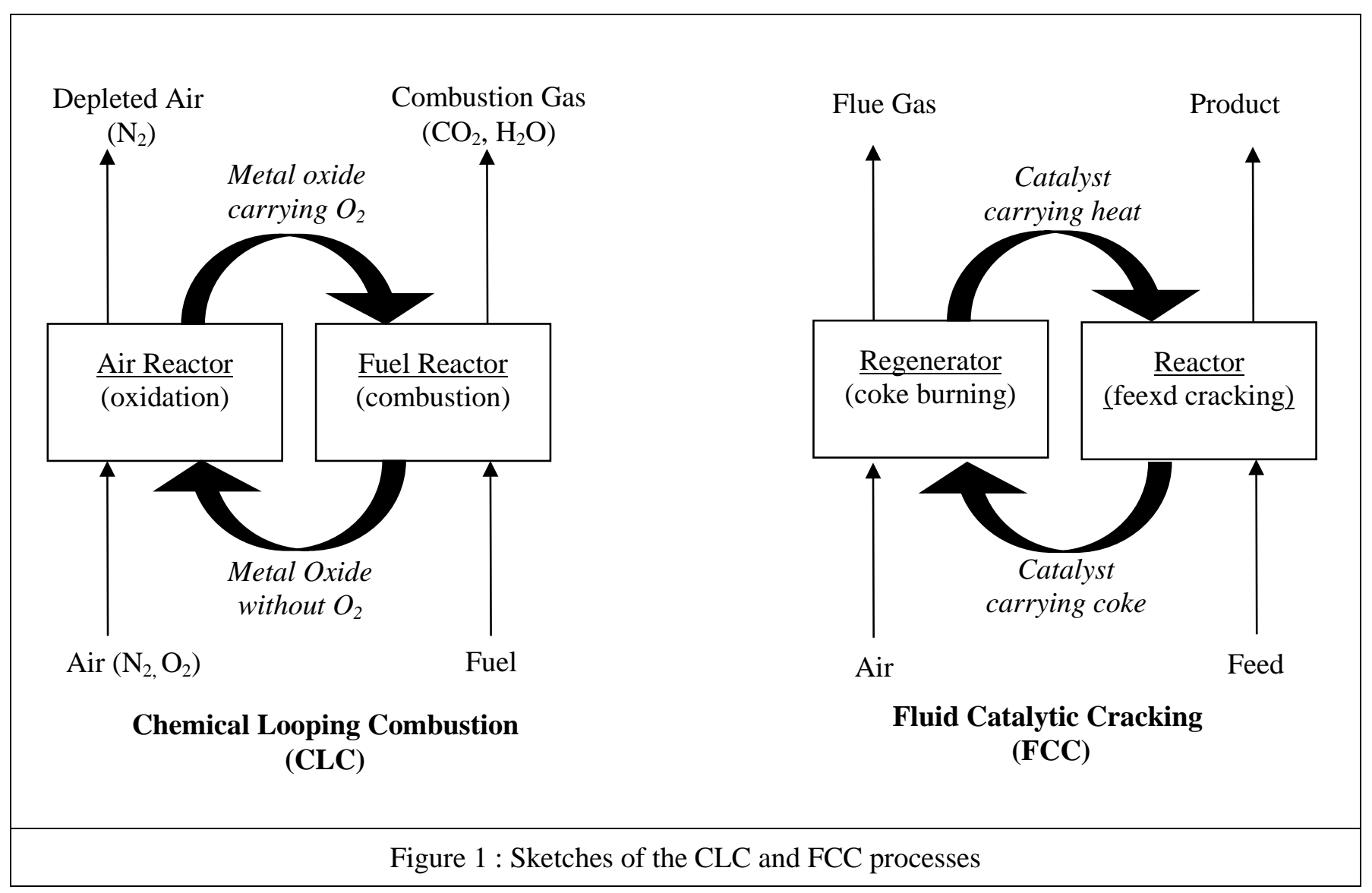

In the FCC process, particles circulate in a loop between the reactor section where the feed is cracked by catalytic reaction and the regenerator section where the coke formed during the reaction is burnt in order to regenerate the catalyst. Therefore in both CLC and FCC processes, particles go through a similar mechanical stress due to different attrition sources like cyclones, gas injections, fluidized beds and so on. Therefore comparing the different 
potential oxygen carriers with FCC catalyst gives a good indication to rank their mechanical resistance and evaluate their potential use at an industrial scale considering only attrition.

This paper presents a method to compare the mechanical resistance to attrition of a Group A FCC catalyst and a Group B oxygen carrier using a jet cup apparatus. First, tests were conducted in a specific attrition unit in order to compare both group A and group B solids.Then a new attrition index is defined and proposed in order to compare attrition observed with powders of significantly different particle size distribution. A CFD study using an Euler/Lagrangian approach was then carried out in order to evaluate the circulation rate of both solids within the cup air jet. Finally an indicator is defined in order to compare the mechanical resistance of both solids from the jet cup attrition results. 


\section{Background}

\subsection{Attrition testing}

Attrition linked to fluidization is a topic of interest intensively studied in the industry. Indeed, generation of fines due to attrition causes many problems such as inventory loss, which has a strong economic impact on the process, as well as change in the flow hydrodynamic with difficulties to operate the units.

Abrasion and fragmentation are the two mechanisms that govern attrition. Abrasion corresponds to daughter particles removed from the surface of a mother particle which generates fines while fragmentation corresponds to daughter particles generated from the splitting of a mother particle which generates intermediate size particles. In fluidization, the physic behind these mechanisms is not quite understood and difficult to model, therefore attrition studies remain correlative. J.Werther and J.Reppenhagen [6] summarize the work and technics used to study particles attrition. Different approaches and many apparatus exist to characterize attrition.

A first approach consist in characterizing attrition due to the principal sources of breakage such as cyclones, gas injections and gas bubbles in fluidized beds. The attrition sources modeling remains correlative with attrition rates expressed in function of attrition source dimensions (injection orifice diameter, bed height, ...), gas properties (velocity, density) and empirical terms depending on the materials. The modeling of attrition sources can then be used in a population balance model in order to predict attrition at an industrial case. J.Werther and E. Hartge [7] used this method to predict the attrition generated in a reactor/regenerator system. Based on this approach, more recently, Kramp et al. [8] made an attempt to simulate attrition in a CLC process. This method is probably the most precise in order to evaluate attrition at industrial scale, however it requires a tedious experimental work and a large quantity of material of interest in order to characterize the different sources of attrition.

A second approach consists in using attrition test in order to evaluate the attrition potential of a material. Such tests allow to rank different materials with respect to their mechanical resistance to attrition and can give useful information during catalyst and process development. Many attrition tests exist. A first category such as the shear and crushing tests evaluate the mechanical resistance of particles applying a well-defined mechanical stress. Discussions exist concerning on how the results of such tests can be correlated to attrition in a circulating fluidized bed. Knight and Bridgwater

[9] showed that when comparing the mechanical resistance of different solids with the shear and crushing tests, the rank is different depending on which test is used. Magnus Rydén et al. [10] found no strong correlation between the crushing test and the attrition data from their continuous chemical looping experiments in reactors at Chalmers University of Technology. A second category of attrition test consist in applying a "less-controlled" mechanical stress by putting particles under a mechanical stress similar to conditions in circulating fluidized beds. For example, the standard method ASTM D-5757 [11] consists in putting 50 grams of a solid sample in a mini-fluidized bed with three vertical air injections at high velocity during 5 hours, the attrition being characterized by the amount of fine elutriated. This method has been design for FCC catalyst only. Cocco et al [12] developed a jet cup test where air is injected tangentially at high velocity in a conical shape container where the particles sample is placed. The high gas velocity injection reproduces the mechanical stress of gas injectors while the tangential inlet induces a swirling flow that reproduces a mechanical stress similar to cyclones. Cocco et al [12] found that their jet cup results correlated well with cyclone attrition data for several FCC catalysts. Moreover, Magnus Rydén et al. [10] found that their jet cup results correlated well with attrition data from their continuous chemical looping experiments at Chalmers University of Technology with Group B oxygen carriers. The jet cup seems to be a promising tool to characterize a solid mechanical resistance to attrition. 


\subsection{Jet Cup attrition index}

Different indexes are used to characterize the attrition generated during a jet cup test. The first method consists in comparing the particles size distribution of the tested sample before and after the test. Figure 2 shows the particle size distributions of a FCC catalyst sample before and after a jet cup test. Cocco et al [12] use two indexes $\mathrm{AI}(20)$ and $\mathrm{AI}(44)$ which corresponds to the weight of particles generated by attrition below respectively $20 \mu \mathrm{m}$ and $44 \mu \mathrm{m}$.

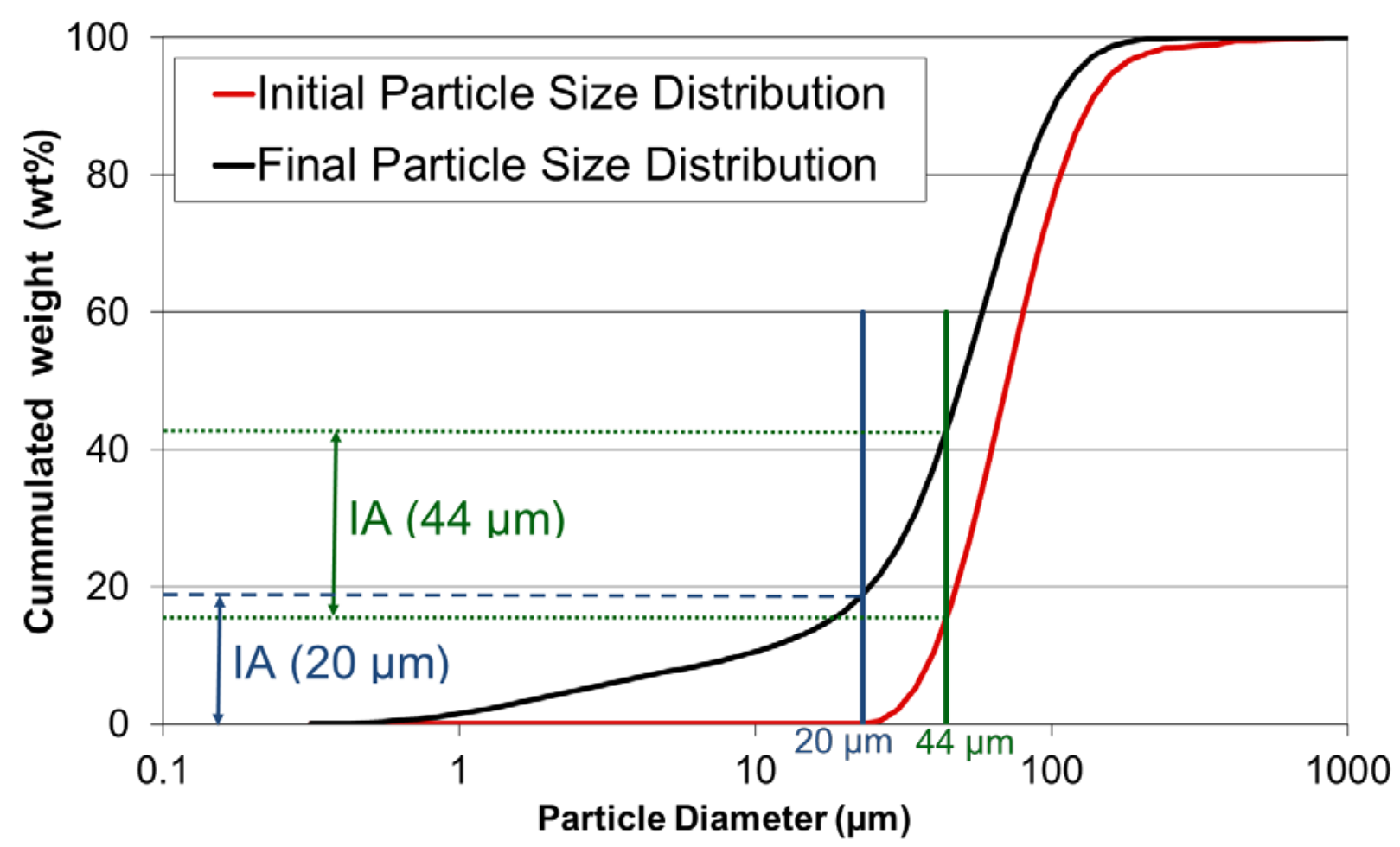

Figure 2: Definition of the attrition indexes used by Cocco et al [12]

These two indexes have limitations when comparing solids with large particles. Indeed, when considering group B powders that are used for the CLC process, generation of fine particles below 20 or 44 microns is not enough to describe particles breakage since the particle size generated by attrition might be higher.

Magnus Rydén et al. [10] characterize the attrition in the jet cup test by measuring the weight of fines that are elutriated and recovered in a filter. The advantage of this method is that it is independent from the measure of particle size distributions which can be challenging. However one problem is that the amount of particles elutriated at a constant gas velocity depends also of the particles properties such as the density. Therefore when comparing two solids with different densities, the amount of fines elutriated to the filter might be lower for the heaviest solids but it does not mean that the attrition rate is lower. 


\subsection{CFD studies carried out on the Jet Cup}

In order to better understand the hydrodynamic and the breakage mechanisms within the jet cup, several Computational Fluid Dynamic (CFD) studies have been carried out.

Cocco et al [12] carried out CFD simulations in order to study the influence of the jet cup shape on the gas-solid flow hydrodynamic. For this purpose they used the commercial code Barracuda ${ }^{\mathrm{TM}}$ from CPFD-Software. Barracuda $^{\mathrm{TM}}$ uses the multiphase particle-in-cell (MP-PIC) method [13][14]. In the code, the gas phase is treated as a continuum in a Eulerian framework solving the averaged Navier-Stokes equations. Particles are treated with a hybrid Eulerian-Lagragian approach where equations are derived from the Liouville equation which governs the transport in an Eulerian framework of a particle distribution function $f(x, u, m, t)$ where $x$ is the spatial location, $u$ and $\mathrm{m}$ are respectively the velocity and the mass of the particle and $\mathrm{t}$ is the time. The particle-phase equations are solved by discretizing the particle distribution function $f(x, u, m, t)$ into computational parcels, each of which represents a certain number of real particles of identical size, velocity and position. For the resolution, computational parcels properties are interpolated onto the Eulerian grid to solve the solid-phase equations, once the equations are solved on the grid, the local properties such as gas velocities, gas pressure gradients and solids stress gradients are interpolated back to the parcel in order to update its position and velocity. Collisions between particles are modeled through the use of a particle stress function [14]. In the study of Cocco et al [12], the particle-fluid drag force was expressed using the Gidaspow drag function [15] which combines the Wen-Yu model and the Ergun model. Parcels of $\mathrm{N}$ particles are assumed to have a drag force of one particle times $\mathrm{N}$. The advantage of the MP-PIC method is that the coupling term between the gas and solid phases takes into account a distribution of particles with different sizes and velocities while a classic Eulerian approach for the solid phase only takes into account an averaged particle diameter and an averaged solid velocity for the interphase coupling term.

Cocco et al [12] simulated jet cup tests in three dimensions with 100 grams of FCC catalyst that represents about $10^{9}$ real particles. The simulations took into account a particle size distribution with a mean diameter of about 80 microns. It is important to notice that attrition is not simulated and therefore the particle size distribution stays constant during the simulations. CFD simulations revealed that with the cylindrical shape jet cup, a large part of the particles remains stagnant. This result was confirmed experimentally with a cold flow study. The problem is that stagnant particles do not go under stress and are not subject to attrition which makes the results from the jet cup test difficult to interpret. Afterwards they studied a jet cup configuration with a conical shape. Both experimental CFD studies confirm that almost all particles were in motion with this configuration, the experimental attrition rates found were higher than with the previous cylindrical shape configuration.

Wei Xu et al [16] used another approach to simulate the jet cup gas-solid hydrodynamic. They carried out CFD simulations using the open source code MFIX-DEM where the gas phase is treated as a continuum in a Eulerian framework while the solid phase is treated in a Lagragian framework using a Discrete Element Method (DEM). Real particles are directly represented and the main advantage of this approach is that particles inter-collisions are directly detected and modeled using the soft-sphere approach [17]. Moreover, Wei Xu et al [16] also implemented a model for particle size reduction due to chipping and abrasive wear from particle-particle and particle-wall interactions. The particle interactions are therefore described in a more precise way and at a lower physical scale compared to the MP-PIC method presented before. However with the DEM approach the number of particles is limited by the expensive computational cost of the method.

Wei Xu et al [16] simulated a jet cup in two dimensions with about $10^{3}$ particles taken into account. Both polydispersed and monodispersed particle size distributions were simulated with particle size going from 200 to 600 microns. Moreover, the particle size is limited at 100 microns in order to avoid numerically the generation by attrition of particles smaller than this diameter. They studied the influence of different parameters on the attrition rate: the air jet velocity, the initial diameter of a mono-dispersed distribution going from 200 to 600 microns, the particles density and the jet cup shape.

First, they found that attrition increases with the air jet velocity. Then there was no direct correlation between the attrition and the initial diameter of the mono-dispersed distribution. The attrition decreases with the particle density the explanation being that although higher density can increase the particle inertia, it will reduce the particle mobility that appears to be more dominant in the attrition process. Finally, they found that changing the shape of the jet cup can create regions where particles are stagnant and therefore the attrition rates is decreased, this is confirmed by the experimental work done by Cocco et al [12]. 


\section{Experimental}

\subsection{Material powder}

Two solids are used for the study presented in this paper. First, a group A FCC equilibrium catalyst with a particle density of $1450 \mathrm{~kg} / \mathrm{m}^{3}$ and a mean particle diameter $\left(\mathrm{dp}_{50}\right)$ of 70 microns. Second a group B oxygen carrier with a particle density of $3600 \mathrm{~kg} / \mathrm{m}^{3}$ and a mean particle diameter $\left(\mathrm{dp}_{50}\right)$ of 180 microns. The particle size distribution of both solids can be found in Figure 3.

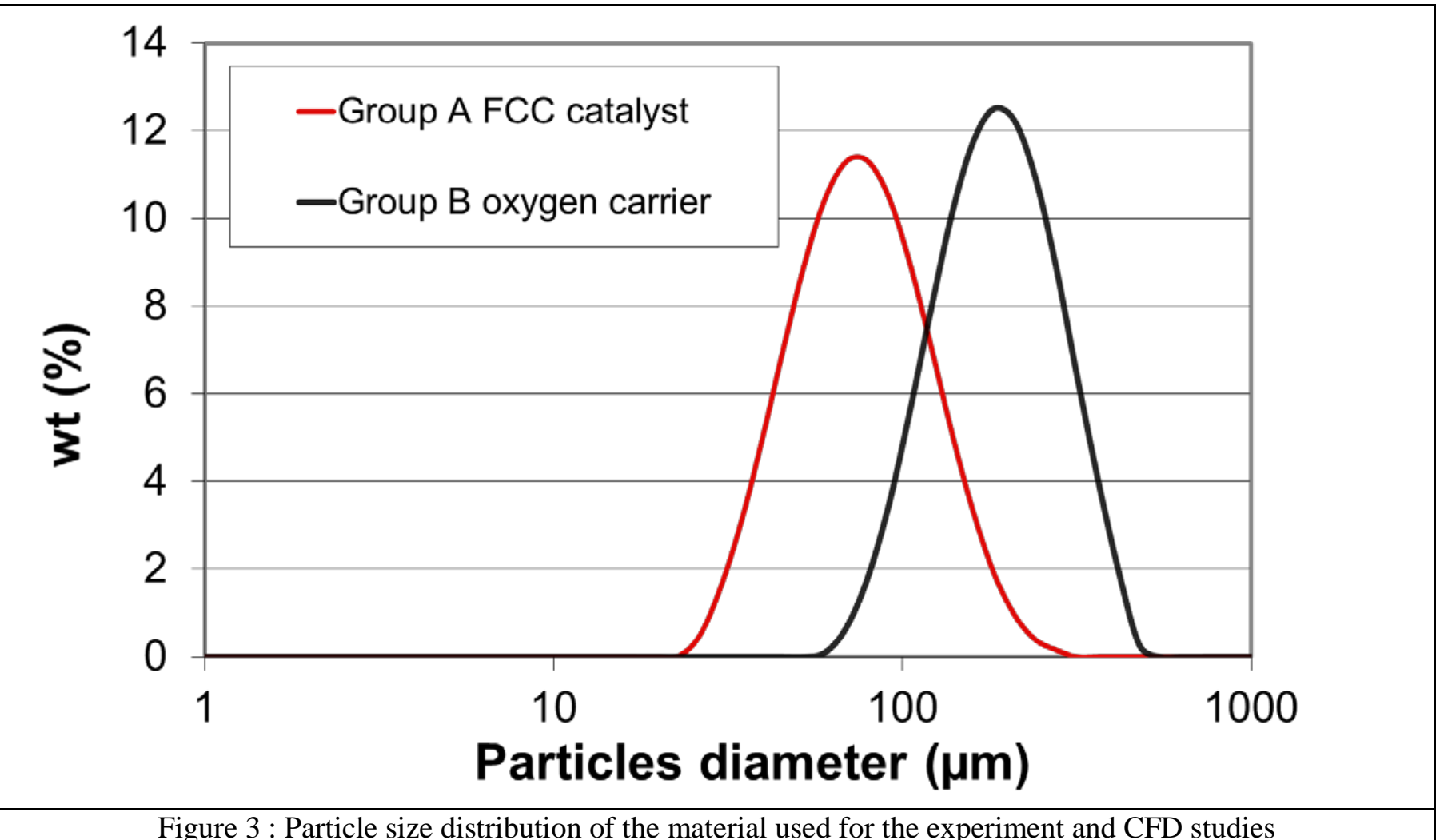

Figure 3 : Particle size distribution of the material used for the experiment and CFD studies 


\subsection{Jet cup attrition testing}

The jet cup used for the attrition testing is presented in Figure 4. It consists in a conical cup where air is injected tangentially in the bottom at high velocity through a $5 \mathrm{~mm}$ diameter orifice. The jet cup is connected to a disengagement vessel where the superficial air is low which allows particles above a certain size to go back into the jet cup. Elutriated fines are collected with a filter placed into the disengagement vessel.

The air flowrate is controlled with a flowmeter brooks 2580S. The accumulation of particles on the filter makes the pressure in the vessel increasing which affects the air jet velocity. For this reasons a maximum pressure variation of 100 mbars is tolerated during the test. In order to limit electrostatic effects that make particles stick to the walls, air was humidified before entering the jet cup.

After testing, materials inside the jet cup and on the filter were weighed. A material balance was conducted to ensure that at least $95 \%$ of the material was accounted for. The attrition generated is characterized with the difference between the particle size distribution before and after the test. The particle size distribution at the end of the test is reconstructed with the particles collected on the filer and inside the cup. Particle size distributions are measured with a laser technique using an apparatus supplied by Malvern company.

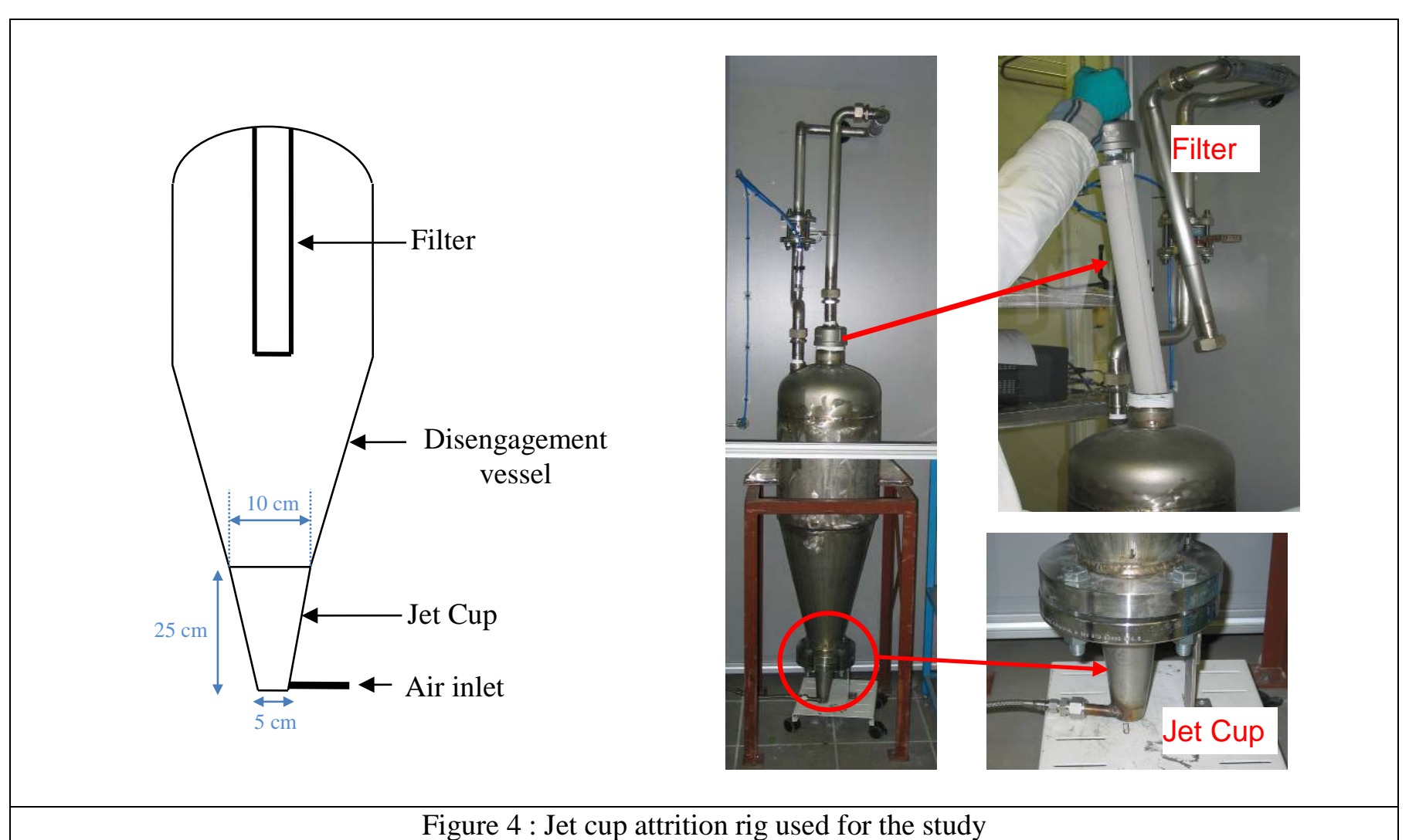

Figure 4 : Jet cup attrition rig used for the study 
Figure 5 and Figure 6 show the particle size distributions (PSD) of jet cup tests carried out respectively on the Group A FCC catalyst and the Group B oxygen carrier. The red and black curves correspond respectively to the initial and the final particle size distributions. The blue curve correspond to the difference between the initial and the final particle size distribution. The positive area delimited by the differential blue curve corresponds to the amount of particles generated by attrition while the negative area corresponds to the amount of particles which were attrited. When the blue curve cut the $x$-axis it indicates the maximum diameter of the particles generated by attrition which is shown by the red arrow on the Figures. When considering large particles such as the oxygen carrier studied, attrition indexes based on the generation of fine particles below 20 or 44 microns are not sufficient to describe particle breakage mechanisms as shown in Figure 6 where the maximum diameter of the particles generated by attrition is 110 microns. Therefore in order to compare both solids on the same basis, we introduced a new attrition index that does not depend upon a given particle size. This index is based on the total percentage of particles generated by attrition which corresponds to the positive area delimited by the differential blue curve shown with the green lines on Figure 5 and Figure 6. This index is referred as TPGI (Total Particles Generated Index) in the rest of the paper.

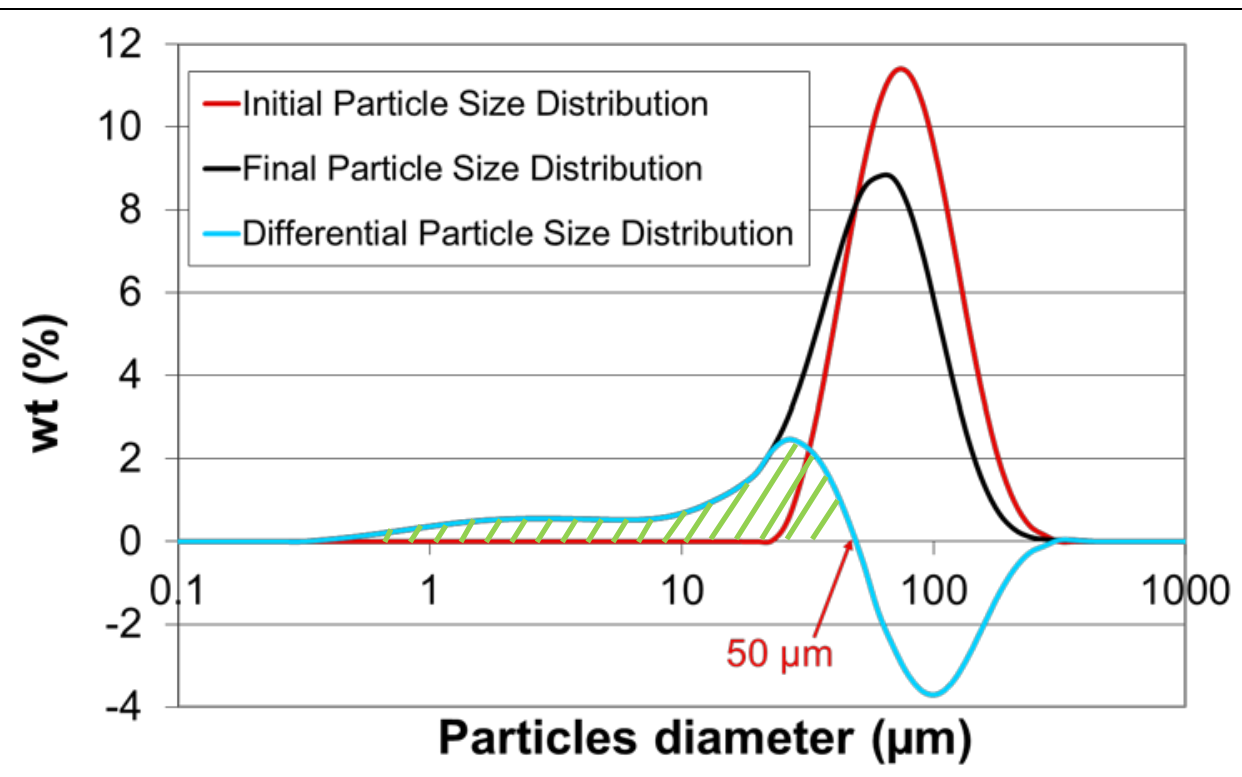

Figure 5 : Group A FCC catalyst ; Particle Size Distributions for a jet cup test ; sample mass of 100 grams air jet velocity: $90 \mathrm{~m} / \mathrm{s}$; test duration: 6 hours

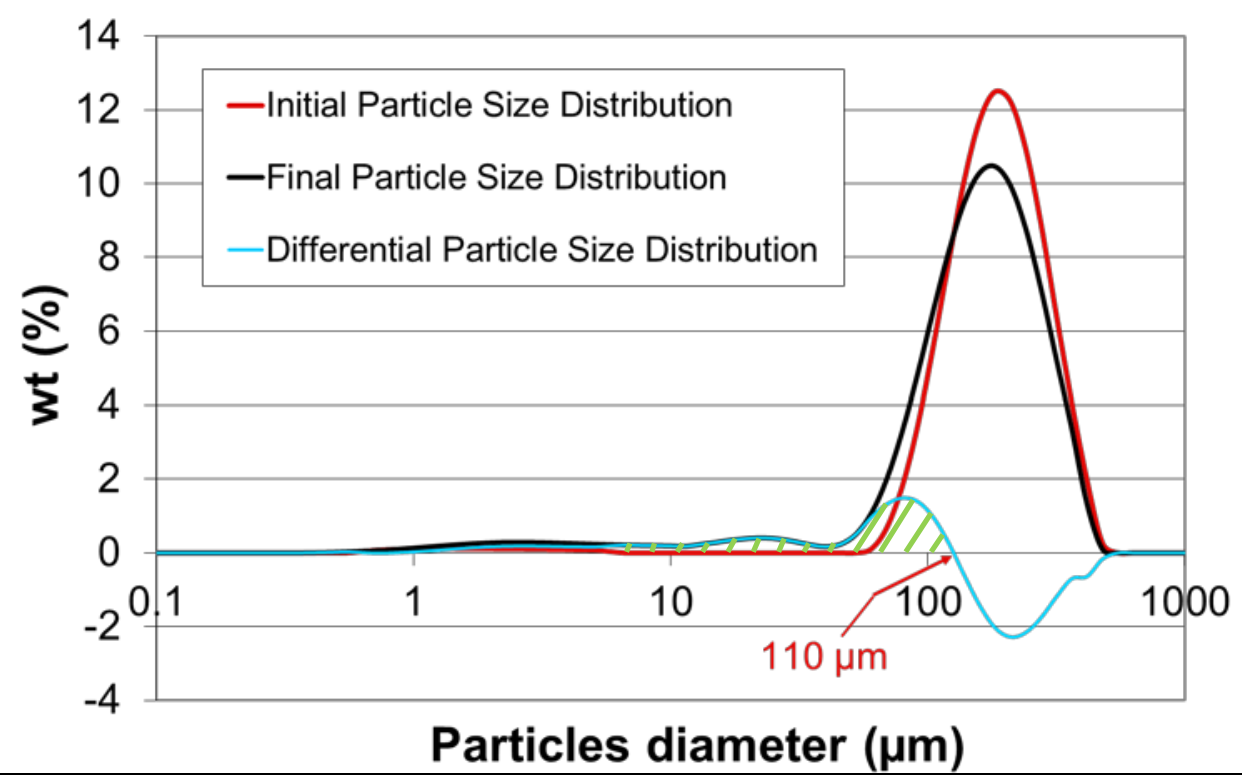

Figure 6 : Group B oxygen carrier ; Particle Size Distributions for a jet cup test ; sample mass of 250 grams air jet velocity: $90 \mathrm{~m} / \mathrm{s}$; test duration: 6 hours 


\subsection{CFD simulation}

A CFD study using the software Barracuda ${ }^{\mathrm{TM}}$, presented in chapter 2.3, was carried out in order to better understand the gas-solis flow hydrodynamic in the jet cup. The domain simulated is presented in Figure 7. Only part of the disengagement vessel is taken into account. A pressure value of $101325 \mathrm{~Pa}$ is imposed at the top surface of the geometry with a pressure boundary condition, particles cannot escape. In order to check that the vessel height chosen was not affecting the particles flow, the number of particle impacts on the top surface was monitored during the simulations. This number was low for all simulations which validates the geometry simulated.

The air injection is controlled with a mass flow boundary condition. The air density and viscosity are automatically calculated by the software according to the air temperature which is fixed at $25^{\circ}$ celcius. The solids density and particle size distribution are taken from the experimental values presented in chapter 3.1. The objective of the simulation is to determine particle circulation pattern in the jet cup. Attrition is not simulated and the particle size distribution remains constant during the simulations.

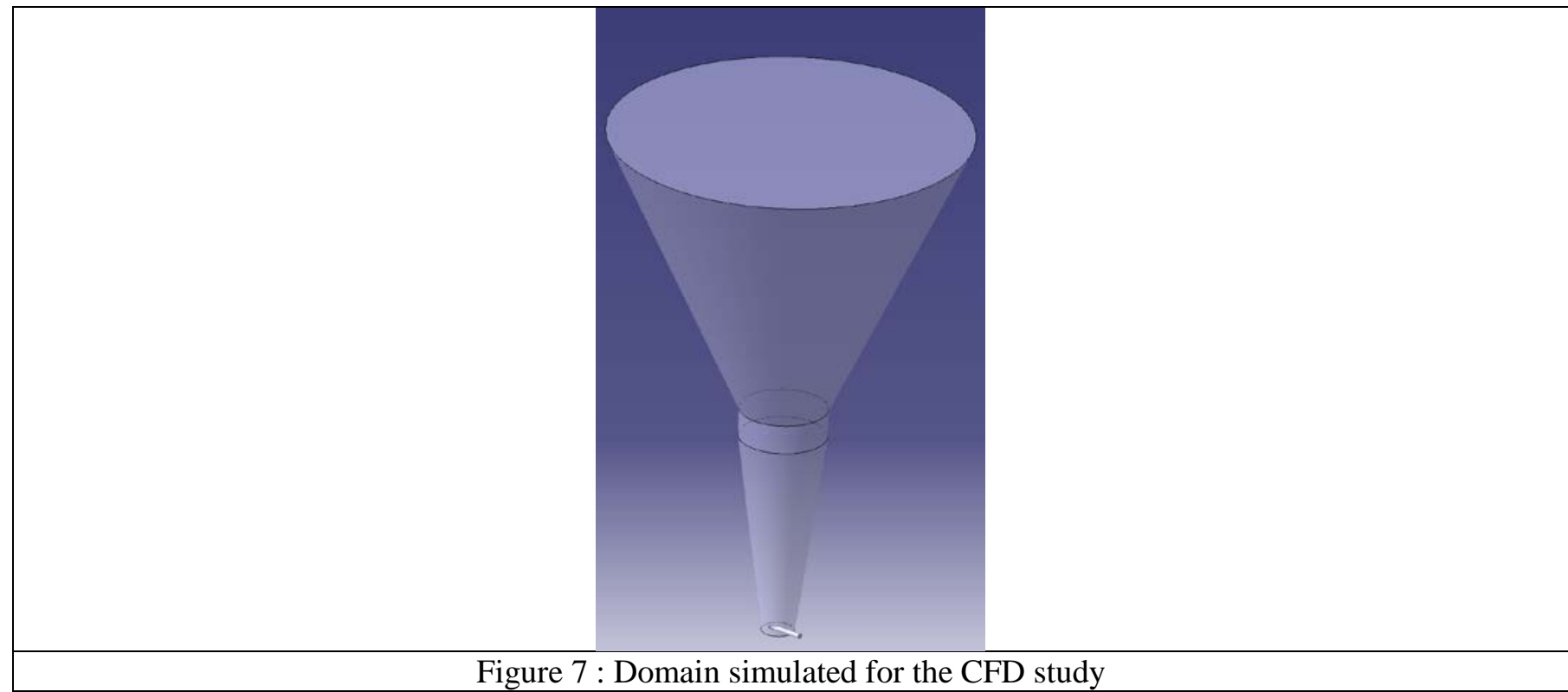

One of the reason CFD simulations were carried out is to evaluate the particles circulation within the air jet at the bottom of the cup, that is to say how many times in average the particles will go through the air jet during a certain test duration. For this purpose, a virtual plane is set just above the air injection as shown in Figure 8. 
Barracuda allows tracking the cumulated mass flow rate of particles going up and down through a virtual plane. Then we defined the particles circulation within the air jet PC_1 as follow:

\begin{tabular}{|c|c|c|c|}
\hline \multirow{2}{*}{$P C_{-} 1\left(s^{-1}\right)=$} & Cumulated mass flowrate going down through the virtual plane & 1 & \multirow{2}{*}{ Equ. 1} \\
\hline & Solid Sample mass & $\overline{\text { Simulation time }}$ & \\
\hline
\end{tabular}

PC_1 represents a percentage of inventory passing into the air jet per second. For example, when simulating a jet cup test with a 100 grams inventory, if after ten seconds there is 200 grams of cumulated particles that went down through the virtual plane, PC_1 is equal to $0.2 \mathrm{~s}^{-1}$ which means than in one second $20 \%$ of the inventory passed into the air jet. With this definition of PC_1, we assume that the flow is homogeneous, that all particles go exactly the same number of time in the air jet. However, there is the possibility that some particles remain stagnant while others go several times within the air jet. In order to evaluate the homogeneity of the solid flow, two groups of particles within the solid inventory are taken randomly as tracers and two particles circulation rates PC_tracer1 and PC_tracer2 are calculated as follow:

\begin{tabular}{|l|l|}
\hline$P C_{-}$tracer $1\left(s^{-1}\right)=\left(\frac{\text { Cumulated tracer1 mass flowrate going down through the virtual plane }}{\text { Tracer 1 mass }}\right) \times \frac{1}{\text { Simulation time }}$ & Equ. 2 \\
\hline$P C_{-}$tracer $2\left(s^{-1}\right)=\left(\frac{\text { Cumulated tracer 2 mass flowrate going down through the virtual plane }}{\text { Tracer 2 mass }}\right) \times \frac{1}{\text { Simulation time }}$ & Equ. 3 \\
\hline
\end{tabular}

Figure 9 presents pictures taken during the simulation of 100 grams of FCC catalyst. The first picture shows the solid volume fraction of the entire sample, while the two other pictures show the position of particles of respectively tracer $n^{\circ} 1$ and tracer $n^{\circ} 2$.

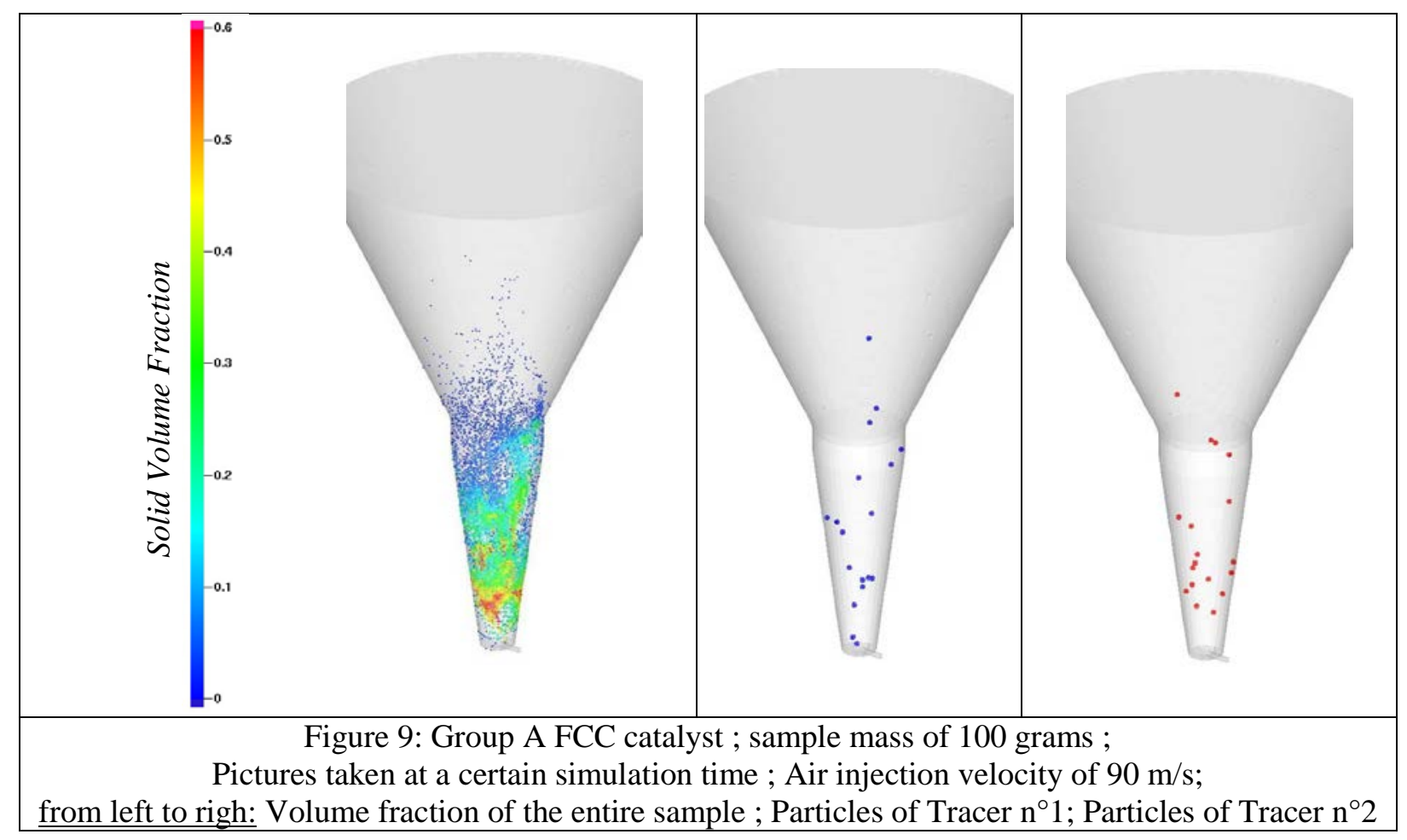

The comparison of the circulation obtained with two random groups of particles (PC_tracer1 and PC_tracer2) and the circulation obtained with the entire inventory (PC_1) gives an estimation on how homogeneous is the flow. Indeed, in the case the three values are close it means that all the particles are circulating in the same way therefore there is no stagnant region and the flow is homogeneous. In the opposite case, it means that the solid is heterogeneous. 


\section{Results}

\subsection{Jet air velocity}

The first parameter to determine was the velocity of the air injection to consider. For this purpose, several tests with different air jet velocity were carried out. Figure 10 presents the Total Particle Generated Index (TPGI) against the air jet velocity for tests of one hour carried out on 100 grams of the Group B oxygen carrier.

Two ranges of velocity can be pointed out. In the first range of velocity from $25 \mathrm{~m} / \mathrm{s}$ to about $110 \mathrm{~m} / \mathrm{s}$, the TPGI increases moderately with respect to the air jet velocity. This corresponds to the zone where abrasion phenomena are dominant. Figure 11 shows the initial and final Particle Size Distribution for the test with an air injection of 90 $\mathrm{m} / \mathrm{s}$. The difference between the two curves is a typical example of abrasion where only fines are generated from the breakage of the big particles. In the second range of velocities from about $110 \mathrm{~m} / \mathrm{s}$ to $180 \mathrm{~m} / \mathrm{s}$, the TPGI increases dramatically with respect to the air jet velocity, it corresponds to the zone where fragmentation phenomena are dominant. Figure 12 shows the initial and final Particle Size Distribution for the test with an air injection of $180 \mathrm{~m} / \mathrm{s}$. The difference between the two curves is a typical example of fragmentation where the breakage of the big particles leads to intermediate size particles.

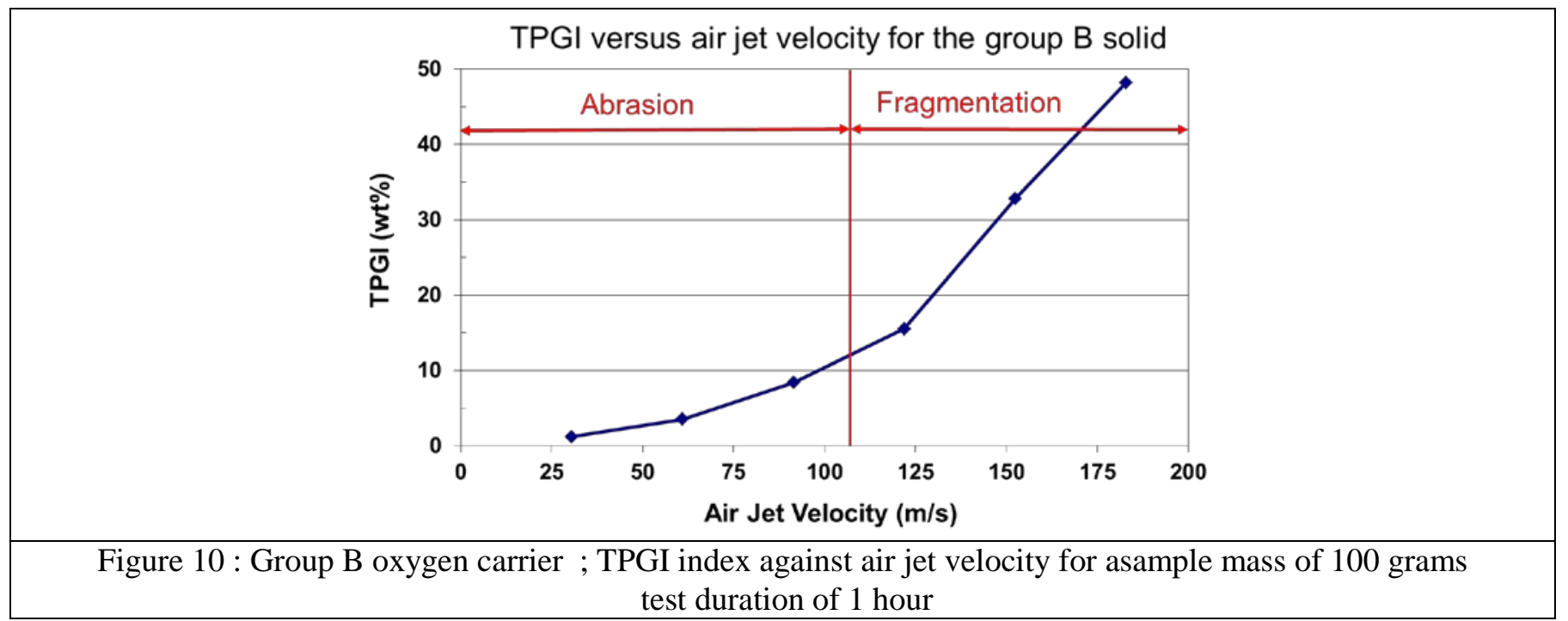

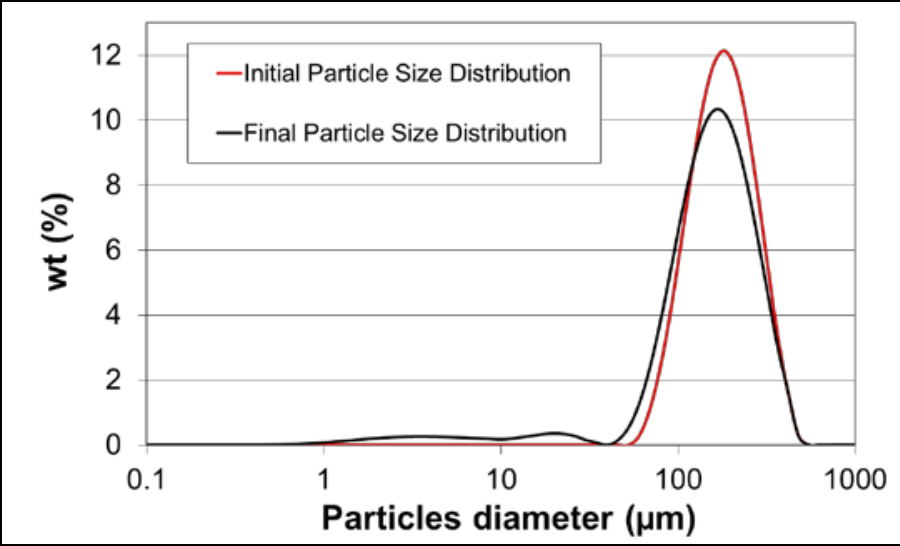

Figure 11 : Initial and Final Particle Size Distribution for a test with 100 grams of group B particles during one hour ; Air Injection velocity $=90 \mathrm{~m} / \mathrm{s}$

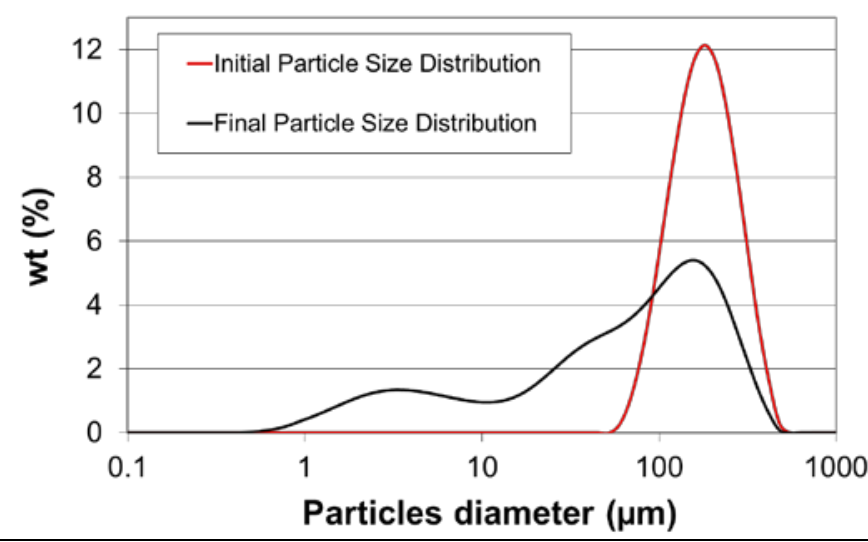

Figure 12 : Initial and Final Particle Size Distribution for a test with 100 grams of group B particles during one hour ; Air Injection velocity $=\mathbf{1 8 0} \mathrm{m} / \mathrm{s}$

From these results, it was decided to take an air injection velocity for the comparison method at the limit between the zone where abrasion phenomena are dominant and the zone where fragmentation is dominant. The velocity value chosen is therefore $90 \mathrm{~m} / \mathrm{s}$ which is also well known to be a suitable velocity value for FCC catalyst attrition testing. 


\subsection{Influence of the solid sample mass and the test duration}

After choosing an air injection velocity value, the other parameters to determine for the jet cup testing method were the amount of solids to put in the jet cup and the test duration. For this purpose, two separate studies were carried out.

In the first study, the test duration is constant and the solid sample mass is changed. The motion of particles in the jet cup is generated by the high velocity air jet, therefore one assumption can be that the attrition generated in the jet cup will be proportional to the contact frequency between the high velocity air jet and the particles. For a fixed test duration, when the sample mass increases, the number of particles increases as well and each particle will go in average less times into the air jet. The contact frequency between particles and the air jet is therefore inversely proportional to the sample mass. For this reason, Figure 13 shows the Total Particle Generated Index (TPGI) plotted against the inverse of the mass for the tests on the Group B oxygen carrier. The Total Particle Generated Index increases almost linearly with respect to the inverse of the solid sample mass. This results verify the assumption that attrition is proportional to the contact frequency between particles and the high velocity air jet.

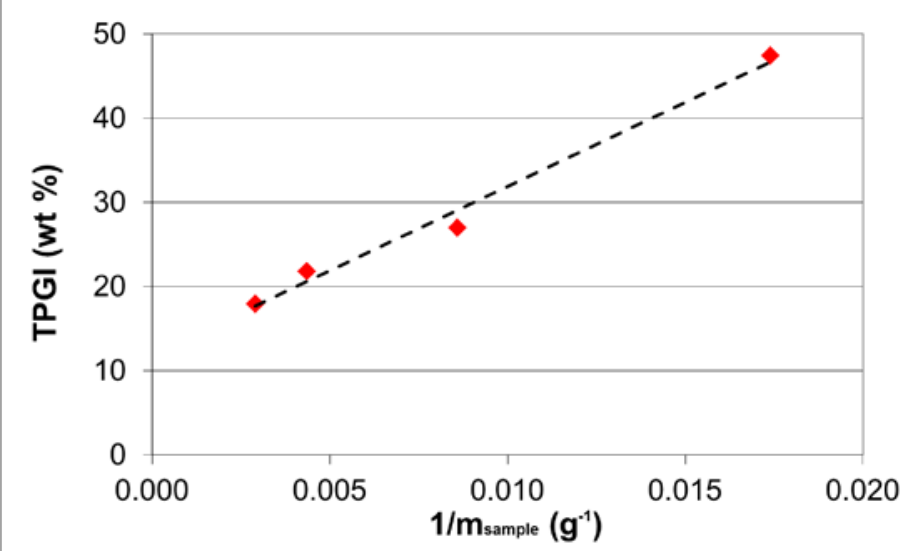

Figure 13 : Group B oxygen carrier ; TPGI against the inverse of the sample mass ; Air injection velocity of $90 \mathrm{~m} / \mathrm{s}$; Test duration of 16 hours

In the second study, the solid sample mass is fixed and the test duration is changed. Figure 14 presents the Total Particle Generated Index (TPGI) plotted against the test duration. Again, the TPGI increases almost linearly with respect to the test duration. The conclusion is the same than with the results presented in Figure 13, attrition generated in the jet cup is proportional to the frequency of contact between particles and the air jet. When increasing the test duration for a fixed sample mass, particles go more times within the air jet, and the attrition generated increases.

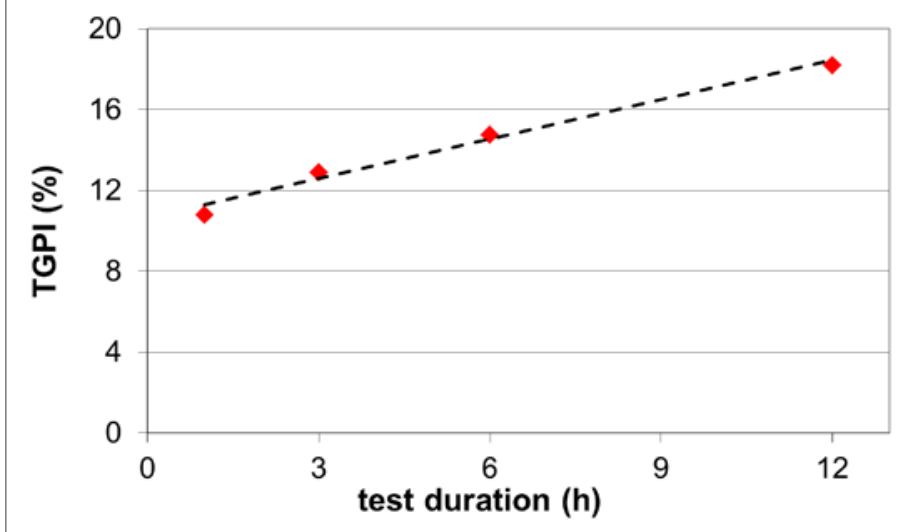

Figure 14 : Group B oxygen carrier ; TPGI against the test duration ; Air injection velocity of $90 \mathrm{~m} / \mathrm{s}$; Sample mass of 250 grams 


\subsection{Jet Cup CFD study}

Results from Figure 13 and Figure 14 show that attrition in the jet cup is proportional to the number of times particles pass into the high velocity air jet. However, solids with different physical properties such as the two solids of interest in this paper are likely to have a different flow pattern with a different solid circulation into the air jet. As a consequence, the average mechanical stress applied on particles for both solids will be different. Therefore, in order to compare both solids on the same basis, it is necessary to determine the particles circulation rate in the high velocity air jet to evaluate if particles go through a similar mechanical stress. This information being unfortunately hardly accessible through experiments, a CFD study was carried out instead. The particles circulation is determined for both Group A FCC particles and Group B oxygen carrier using the method presented in chapter 3.3.

Three simulations were carried out. First the reference case with 100 grams of group A FCC particles was simulated. Then two other cases were simulated with the Group B oxygen carrier particles, one with the same mass than the reference case, the other one with the same initial particles volume than the reference case.

As expected, the flow pattern obtained for the simulations with the Group B oxygen carrier is quite different than with the Group A FCC catalyst as shown in Figure 15. With the Group A FCC catalyst, all particles are suspended and go once in a while into the air jet where they are carried upward with a high velocity. With the group B oxygen carrier, there is an accumulation on the side of the air injection. Particles go into the air jet, they are then carried upward with a high velocity and fall at the top of the particles accumulation where they go slowly toward the air injection.

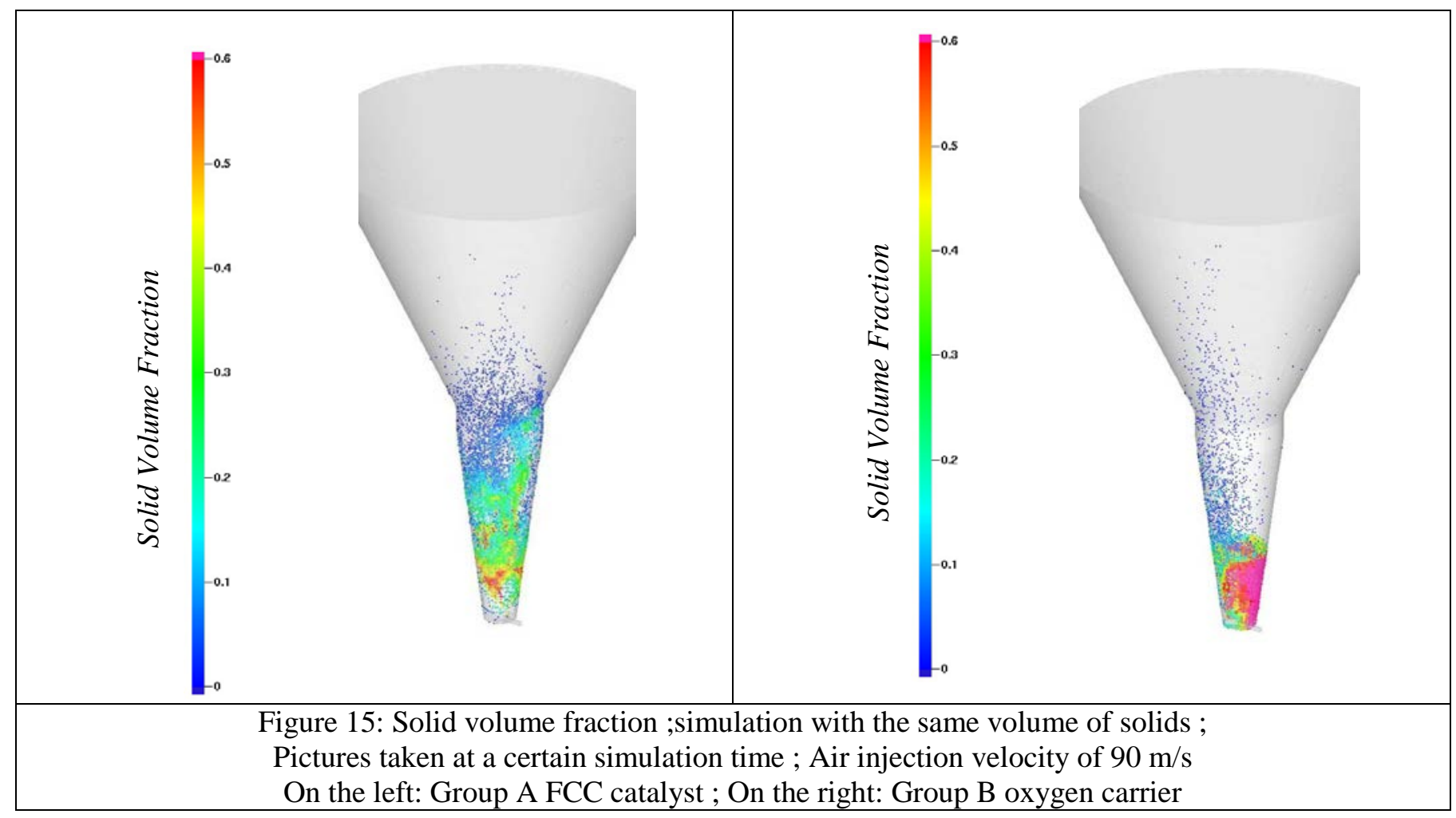


The results obtained for the three particle circulation indexes PC_1, PC_tracer1 and PC_tracer2 are presented in Table 1.

\begin{tabular}{|c|c|c|c|c|c|c|c|c|}
\hline $\begin{array}{c}\text { Simulation } \\
\text { number }\end{array}$ & Solid & $\begin{array}{c}\text { Solid } \\
\text { Density } \\
\left(\mathrm{kg} / \mathrm{m}^{3}\right)\end{array}$ & $\begin{array}{c}\text { Solid } \\
\text { Mean } \\
\text { Diameter } \\
\mathrm{D}_{50}(\mu \mathrm{m})\end{array}$ & $\begin{array}{c}\text { Solid } \\
\text { Sample } \\
\text { mass }(\mathrm{g})\end{array}$ & $\begin{array}{c}\text { Initial } \\
\text { Volume in } \\
\text { Jet Cup } \\
\left(\mathrm{cm}^{3}\right)\end{array}$ & $\begin{array}{c}\text { PC_1 } \\
\left(\mathrm{s}^{-1}\right)\end{array}$ & $\begin{array}{c}\text { PC_tracer1 } \\
\left(\mathrm{s}^{-1}\right)\end{array}$ & $\begin{array}{c}\text { PC_tracer2 } \\
\left(\mathrm{s}^{-1}\right)\end{array}$ \\
\hline 1 & $\begin{array}{c}\text { Group A } \\
\text { FCC } \\
\text { catalyst }\end{array}$ & 1450 & 70 & 100 & 115 & $\mathbf{0 . 2 6}$ & $\mathbf{0 . 2 5}$ & $\mathbf{0 . 2 8}$ \\
\hline 2 & $\begin{array}{c}\text { Group B } \\
\text { Oxygen } \\
\text { carrier }\end{array}$ & 3600 & 180 & 100 & 46 & $\mathbf{0 . 6 8}$ & $\mathbf{0 . 6 5}$ & $\mathbf{0 . 6 9}$ \\
\hline 3 & $\begin{array}{c}\text { Group B } \\
\text { Oxygen } \\
\text { carrier }\end{array}$ & 3600 & 180 & 250 & 115 & $\mathbf{0 . 2 4}$ & $\mathbf{0 . 2 5}$ & $\mathbf{0 . 2 7}$ \\
\hline
\end{tabular}

Table 1 : Circulation indexes PC_1, PC_tracer1 and PC_tracer2

First, for the three simulations the particle circulations measured with the tracers (PC_tracer1 and PC_tracer2) are similar to the one measured with the entire inventory (PC_1) which show that the solid flow tends to be homogeneous in all cases, there is no stagnant region where particles do not move.

When comparing results for the two simulations conducted with the Group B oxygen carrier, one can see that PC_1 changes with the solid initial inventory. Indeed, the PC_1 frequency is inversely proportional to the inventory (see Table 1). This is consistent with experimental observation reported before. In order to have the same particles circulation into the air jet and therefore a similar mechanical stress apply on particles, the comparison between the FCC catalyst and the oxygen carrier should be done with the same initial volume of particles in the jet cup. Indeed in both cases PC_1 is equal to about $0.25 \mathrm{~s}^{-1}$ (see Table1). It is also important to notice that this conclusion is valid only for the two solids simulated. If another solid with different properties has to be tested then other simulations must be carried out to evaluate its circulation.

Finally, Barracuda allows to track the cumulated impact of particles on the geometry wall. For this purpose an impact number is defined and it is proportional to the particles velocity and mass, a correction factor is then applied according to the impact angle. Barracuda then calculates the cumulated impact number over the entire simulation time. Figure 16 presents the cumulated impact number for the simulations with respectively the Group A FCC catalyst and the Group B oxygen carrier. 


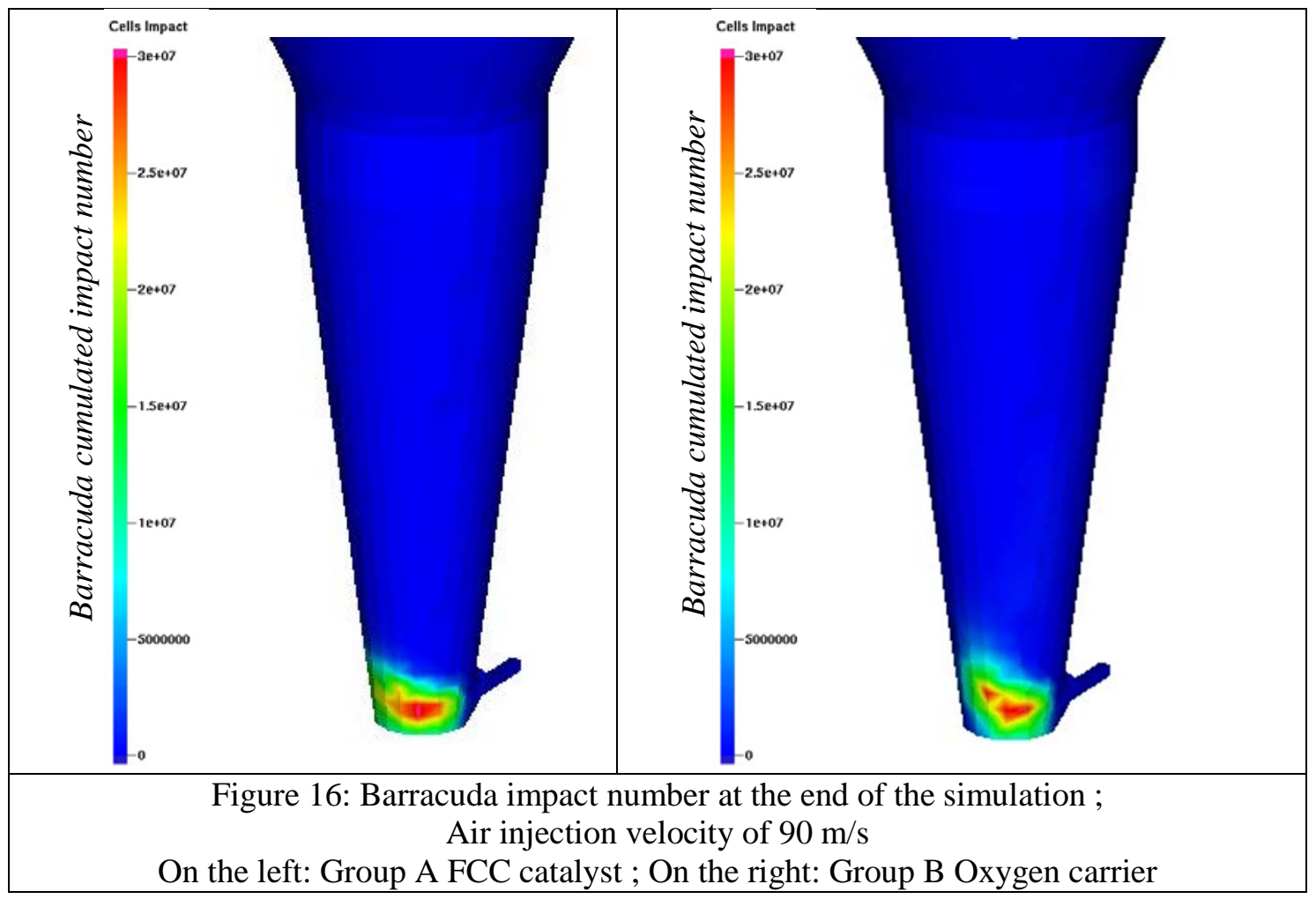

For both solids, the higher cumulated impact number and therefore the higher mechanical stress applied on particles is located exactly on the opposite side of the air injection. Therefore, even if the global hydrodynamic in the jet cup is different for both solid, the mechanical stress applied on particles and therefore the attrition generated in the jet cup is mainly proportional to the particle number of passages in the air jet. 


\subsection{Solid mechanical resistance characterization}

From the previous results, the jet cup test parameters for the comparison of the two solids of interest in this paper have been chosen: the Total Particule Generated Index is used to characterize attrition in the jet cup for both solids, an air injection velocity of $90 \mathrm{~m} / \mathrm{s}$ was chosen and the CFD study suggested that comparison has to be done with the same initial volume of particles in order to have a similar mechanical stress applied on particles for both solids. The last step for the comparison method is to define a parameter that characterize the solid mechanical resistance to attrition.

Figure 17 presents the Total Particle Generated Index (TPGI) against several test durations for both Group A FCC catalyst and Group B oxygen carrier. The comparison was made using the parameters presented previously. For both solids, the TPGI is linearly proportional to the testing time. The particles mechanical resistance is therefore characterized by the TGPI increasing rate against time, and the comparison between solids is made using this parameter. Therefore among two solids of interest in this paper, the Group B oxygen carrier is considered more resistant to attrition with an increase rate of the TPGI versus time of 0,7 which is lower than the one of the Group A FCC catalyst of 2,2.

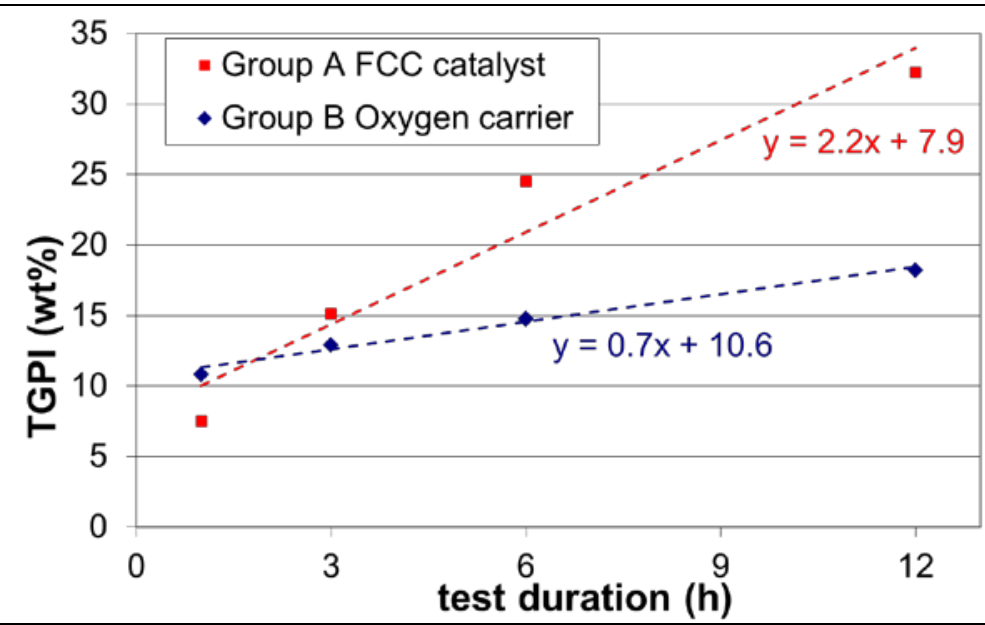

Figure 17 : Comparison of the Group A FCC catalyst with the Group B oxygen carrier TPGI versus test duration ; comparison at iso initial particles volume ; air velocity injection at $90 \mathrm{~m} / \mathrm{s}$ 


\section{Discussion}

Several points can be discussed concerning the results presented before and the comparison method developed in this study.

First, in Figure 17 the Total Particle Generated Index is considered linear over the range of test durations carried out for both solids. However, considering that at time zero hour the attrition index is zero, one can observe that in the range of test durations from zero to one hour, the attrition index increases sharply for both solids. An explanation for this initial sharp increase of attrition is that at the beginning of the test, abrasion phenomena are enhanced until reaching a certain threshold where particles will then break more slowly. This threshold is higher for the Group B oxygen carrier than for the Group A FCC catalyst which is logical since we took equilibrium FCC catalyst that was used in an industrial unit while the oxygen carrier is fresh solid. The attrition index will also reach a threshold for long test durations. Indeed after reaching a certain size, particles will stop breaking. Thus the evolution of the attrition index can be assumed linear only over a certain range of test duration.

Second, for the comparison method presented in this paper the characterization of the attrition generated in the jet cup is based on the measurement of the Particles Size Distributions (PSDs) before and after the test. The results obtained are therefore dependent on the solid sampling and the technic used to measure the PSDs. The solid sampling can be important since only few grams are necessary to measure a PSD and the particle inventory in the cup can reach 300 grams. Then the measurement technic used is also important as it can be sometime challenging to measure the PSDs of dense Group B particles. It is therefore better to use several technics at the same time such as laser and coulter-counter measurements to confirm the results obtained.

The CFD study allowed us to better understand the effect of particle properties on the Jet Cup flow hydrodynamic. It is however important to validate the CFD results with experimental data. The flow pattern obtained from CFD is different for the two solids simulated. This patterns have been validated qualitatively experimentally at the Particle Solid Research Inc (PSRI) on a transparent jet cup. Further work must be done to have a quantitative experimental measurement of the solid circulation rate within the cup air jet.

Finally, this study aims to compare attrition of solids in a non-reactive flow environment. Indeed, no reaction nor thermal stress is applied on the particles during the test. Therefore, the method proposed in this paper only aims to assess attrition mechanisms related to circulation in the process but other aspects, for instance related to temperature or oxydo-reduction cycles have also to be taken into account when considering the attrition at industrial operating conditions. 


\section{Conclusions}

A method to compare the mechanical resistance to attrition of solids from different fluidization groups was developed in this work. In order to deal with small amount s of particle samples, experiments are conducted using lab scale testing with a Jet Cup rig developed by Cocco et al [12]. This is an interesting tool that provided results which correlated well with attrition data from cyclones (Cocco et al [12]) and circulating fluidized bed (Magnus Rydén et al. [10]). Two solids of interest were considered in this study, a Group B oxygen carrier with a density of $3600 \mathrm{~kg} / \mathrm{m}^{3}$ and a mean particle diameter $\left(\mathrm{dp}_{50}\right)$ of 180 microns, and a group A FCC equilibrium catalyst with a particle density of $1450 \mathrm{~kg} / \mathrm{m}^{3}$ and a mean particle diameter $\left(\mathrm{dp}_{50}\right)$ of 70 microns.

First, we defined a new attrition index that does not depend upon a given particle size. This index is based on the total percentage of particles generated by attrition and it is called TPGI (Total Particles Generated Index). This index also gives the possibility to estimate the maximum diameter of particles generated by attrition.

It was found that attrition in the jet cup is proportional to the contact frequency between the air jet and the particles. Therefore it is necessary to estimate the particles circulation within the air jet for each solid tested in order to make sure that particles go through the same mechanical stress. For this purpose, a CFD study using Barracuda ${ }^{\mathrm{TM}}$ was carried out on the two solids of interest. CFD results showed that in order to have the same circulation of particles in the air jet and therefore the same mechanical stress, tests should be carried out with the same initial volume of particles. It is important to notice that this conclusion is valid for the two solids of interest, another CFD study should be done for solids with different properties.

Finally, the particles mechanical resistance is characterized by the TPGPI increase rate against the test duration. This parameter is then be used to compare the solids tested, the oxygen carrier being more resistant than the FCC catalyst in our case. 


\section{Acknowledgements}

This research has been carried out in partnership with the French company Total, their support is gratefully acknowledged. The work of G.Merchat, D.Roux and M.Legast is also gratefully acknowledged.

\section{References}

[1] Juan Adanez, Alberto Abad, Francisco Garcia-Labiano, Pilar Gayan, Luis F. de Diego, Progress in ChemicalLooping Combustion and Reforming technologies, Progress in Energy and Combustion Science Volume 38, Issue 2, April 2012, Pages 215-282.

[2] Thierry Gauthier, Florent Guillou, Stéphane Bourgeon et Hélène Stainton, La combustion en boucle chimique Un procédé en rupture pour le captage du CO2, l’actualité chimique février-mars 2013 n³71-372.

[3] M.M. Yazdanpanah, A. Hoteit, A. Forret, A. Delebarre, T. Gauthier, Experimental Investigations on a Novel Chemical Looping Combustion Configuration, Oil \& Gas Science and Technology - Rev. IFP Energies nouvelles, Vol. 66 (2011), No. 2, pp. 265-275.

[4] H. Stainton , A. Ginet, K. Surla, A. Hoteit, Experimental investigation of CLC coal combustion with nickel based particles in a fluidized bed, Fuel 101 (2012) 205-214.

[5] M.M. Yazdanpanah, A. Forret, T. Gauthier, A. Delebarre, An experimental investigation of L-valve operation in an interconnected circulating fluidized bed system, Powder Technology 221 (2012) 236-244.

[6] Joachim Werther, Jens Reppenhagen, Attrition in Fluidized Beds and Pneumatic Conveying Lines, Fluidization Solids Handling and Processing (1998) 435-491.

[7] Joachim Werther, Ernst-Ulrich Hartge, A population balance model of the particle inventory in a fluidized-bed reactor/regenerator system, Powder Technology 148 (2004) 113- 122.

[8] M. Kramp, A. Thon, E.-U. Hartge, S. Heinrich, J. Werther, The Role of Attrition and Solids Recovery in a Chemical Looping Combustion Process, Oil \& Gas Science and Technology Rev. IFP Energies nouvelles, Vol. 66 (2011), No. 2, pp. 277-290.

[9] Knight P. C, Bridgwater J., Comparison of Methods for Assessing Powder Attrition, Powder Tech., 44:99 (1985)

[10] Magnus Rydén, Patrick Moldenhauer, Simon Lindqvist, Tobias Mattisson, Anders Lyngfelt, Measuring attrition resistance of oxygen carrier particles for chemical looping combustion with a customized jet cup, Powder Technology (2014), doi: 10.1016/j.powtec.2014.01.085

[11] ASTMD5757-11: Standard Test Method for Determination of Attrition of FCC Catalysts by Air Jets, ASTM, Philadelphia, United States, 2011.

[12] R. Cocco, Y. Arrington, R. Hays, J. Findlay, S.B.R. Karri, T.M. Knowlton, Jet cup attrition testing, Powder Technology 200 (2010) 224-233.

[13] M.J. Andrews, P.J. O'Rourke, Int. J. Multiphase Flow 22 (1996) 379-402. 
[14] D.M. Snider, An Incompressible Three-Dimensional Multiphase Particle-in-Cell Model for Dense Particle Flows, Journal of Computational Physics 170, 523-549 (2001)

[15] Gidaspow, D. (1994). Multiphase Flow and Fluidization. Continuum and Kinetic Theory Description. Academic Press, Boston.

[16] Wei Xu, David S. DeCroix , Xin Sun, Mechanistic based DEM simulation of particle attrition in a jet cup, Powder Technology 253 (2014) 385-392

[17] Y. Tsuji, T. Tanaka and T. Ishida, Lagrangian numerical simulation of plug flow of cohesionless particle in a horizontal pipe, Powder Technology, 71 (1992) 239-250 